\title{
Anatomy of phreatic eruptions
}

\author{
Corentin Caudron ${ }^{1,2,3,4^{*}+}$ (0), Benoit Taisne ${ }^{1,5 \dagger}$, Jurgen Neuberg ${ }^{6 \dagger}$, Arthur D. Jolly ${ }^{7 \dagger}$, Bruce Christenson ${ }^{7 \dagger}$,
}

Thomas Lecocq ${ }^{3 \dagger}$, Suparjan ${ }^{8 \dagger}$, Devy Syahbana ${ }^{8 \dagger}$ and Gede Suantika ${ }^{8 \dagger}$

\begin{abstract}
This study investigates phreatic eruptions at two similar volcanoes, Kawah ljen (Indonesia) and White Island (New Zealand). By carefully processing broadband seismic signals, we reveal seismic signatures and characteristics of these eruptions. At both volcanoes, the phreatic eruptions are initiated by a very-long-period (VLP) seismic event located at shallow depths between 700 and $900 \mathrm{~m}$ below the crater region, and may be triggered by excitation of gas trapped behind a ductile magma carapace. The shallow hydrothermal systems respond in different ways. At Kawah ljen, the stress change induced by VLPs directly triggers an eigenoscillation of the hyperacidic lake. This so-called seiche is characterized by long-lasting, long-period oscillations with frequencies governed by the dimensions of the crater lake. A progressive lateral rupture of a seal below the crater lake and/or fluids migrating toward the surface is seismically recorded $\sim 15 \mathrm{~min}$ later as high-frequency bursts superimposed to tilt signals. At White Island, the hydrothermal system later ( $\sim 25 \mathrm{~min}$ ) responds by radiating harmonic tremor at a fixed location that could be generated through eddy-shedding. These seismic signals shed light on several aspects of phreatic eruptions, their generation and timeline. They are mostly recorded at periods longer than tens of seconds further emphasizing the need to deploy broadband seismic equipment close to active volcanic activity.
\end{abstract}

Keywords: Volcanic monitoring, Phreatic eruption, Volcanic lake, Broadband seismology

\section{Introduction}

To date, significant progress has been made in forecasting volcanic eruptions involving substantial magma movement by using seismicity, deformation and gas emission monitoring (e.g., 2010 Merapi eruption, Surono et al. 2012). Nevertheless, it remains challenging to detect and understand the signals preceding and accompanying phreatic explosions as those are lacking any extrusion of juvenile magma at the surface. Despite making up only $8 \%$ of volcanic activity, phreatic eruptions are responsible for $20 \%$ of casualties (Mastin and Witter 2000). These eruptions are also capable of injecting ash to high altitudes (several kilometers), resulting in severe impacts upon aviation and, therefore, on the overall economy. Hence, it is of paramount importance to understand the processes leading to phreatic eruptions and their geophysical signature that could be recorded by volcano

\footnotetext{
*Correspondence: Corentin.Caudron@gmail.com

${ }^{\dagger}$ All the authors contributed equally.

${ }^{4}$ Department of Geology, Ghent University, Campus Sterre, S8, Krijgslaan 281, 9000 Ghent, Belgium

Full list of author information is available at the end of the article
}

monitoring networks. Following Stix and Moor (2018), phreatic eruptions encompass steam-driven explosions generated by magma intruding fluvial sediments and aquifers, lava or pyroclastic flows interacting with surface water, geyser-like explosions driven by depressurization of near boiling-point subterranean geothermal water, and volcanic eruptions expelling hydrothermal systems formed during periods of repose (e.g., Barberi et al. 1992; Rouwet et al. 2014).

In this study, we investigate broadband seismic signals recorded in the near field [i.e., the source-receiver distance is smaller than or comparable to the radiated wavelength [Aki and Richards (2002), Lokmer and Bean (2010)] during phreatic eruptions at two different volcanoes. Kawah Ijen volcano (East Java, Indonesia, Fig. 1a, b) has the largest hyperacidic crater lake on Earth with a volume of 27-30 million $\mathrm{m}^{3}$, a temperature of $30-45^{\circ} \mathrm{C}$ and a pH of less than 0.5 (Caudron et al. 2015a). Therefore, it is considered to be among the most dangerous volcanoes in Indonesia. Since 2010 several seismometers and lake monitoring sensors (see Caudron et al. 2015b, 2017 for a description) have been installed in the crater area 


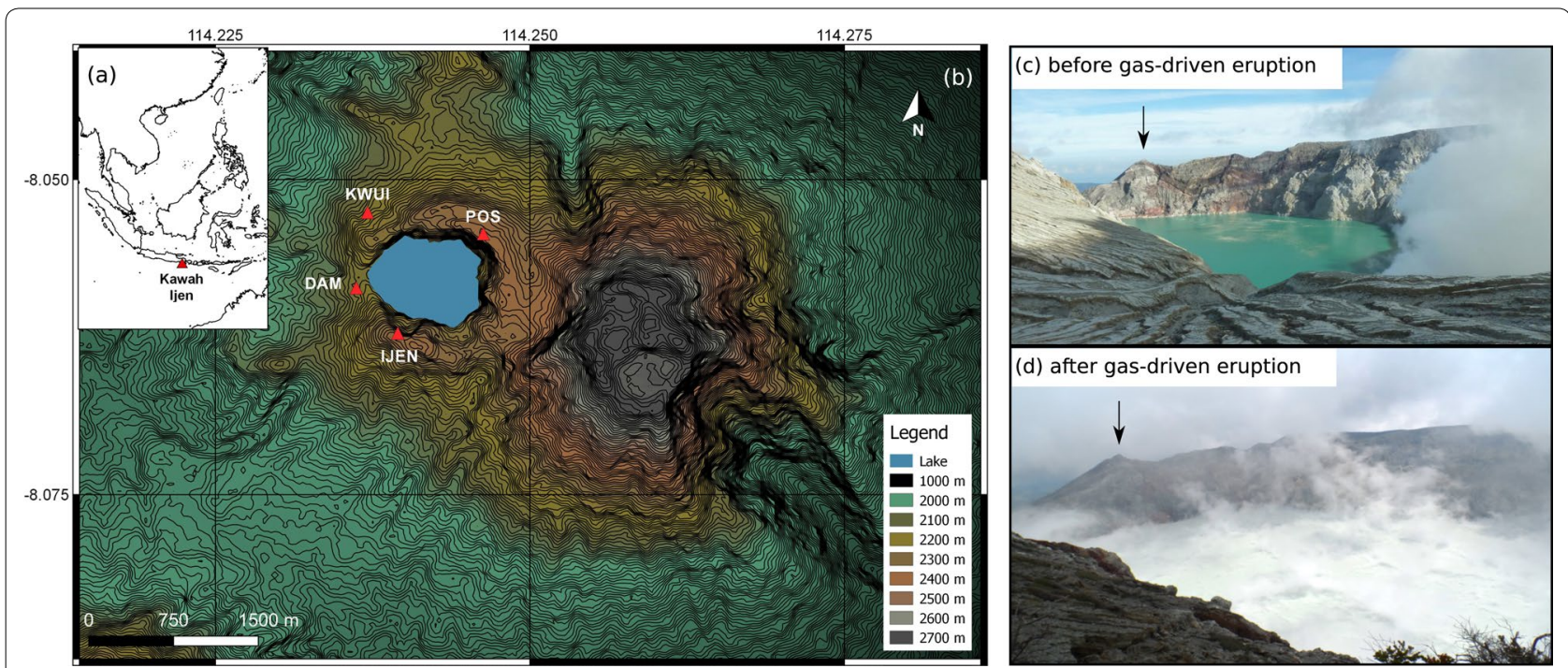

Fig. 1 Kawah ljen phreatic eruption and seismic network. a Kawah ljen location in South East Asia. b Seismic stations locations in the crater (POS and DAM are broadband seismic stations, whereas KWUI and TRWI are short-period seismic stations). c Photograph taken on 11 March, 9 days before the phreatic eruption on 20 March 2013 (the persistent degassing is emitted by the fumarole). d Photograph taken on 27 March 2013, 7 days after the eruption. The arrow indicates a common feature on the photos

(Fig. 1b) providing a high-quality dataset (Caudron et al. 2015a). After 6 years of quiescence, a period of hydrothermal unrest started in 2011 (Caudron et al. 2015b). On 20 March 2013 sulfur miners working in the crater fled the volcano after they heard and felt subsurface explosions followed by an apparent increase in lake level. The photographs taken a week after this event display a lake covered by a white blanket instead of its usual turquoise color (Fig. 1c, d). At the same time, the lake temperature reached $59{ }^{\circ} \mathrm{C}$, the highest value ever recorded. White Island volcano (New Zealand, Fig. 2a, b) also has an active hydrothermal system and has experienced numerous phreatic eruptions in its history (Werner et al. 2008). This study analyzes the seismic data associated with a short-lived phreatic eruption on October 3, 2013 during a period of unrest between August 2011 and January 2014 (Fig. 2c; Chardot et al. 2015).

Due to their extended sensitivity over a wide frequency range and their wide dynamic range, broadband seismic instruments glean a wealth of data and provide invaluable information and insight. However, scrupulous data processing is necessary to reveal very-long-period (VLP) seismic signals with periods of a few tens of seconds and ultra-long-periods (ULP) with periods of several minutes (e.g., Neuberg et al. 1994; Kawakatsu et al. 2000; Kumagai et al. 2010; Chouet and Matoza 2013). This study reveals and examines a variety of seismic signals recorded during the phreatic explosions on both target volcanoes. Similarities and differences are pointed out, and plausible mechanisms and physical models are presented and discussed.

\section{Instrumentation and processing}

At Kawah Ijen volcano, four seismic stations installed in the crater area recorded the March 2013 volcanic activity. Two Trillium 120P broadband seismometers with a corner period of $120 \mathrm{~s}$ which recorded seismic data at a sample rate of $200 \mathrm{~Hz}$ on Taurus digitizers are located on the crater rim (DAM, to the west, and POS to the north, Fig. 1b), whereas one short-period kinemetric seismometer has been deployed on top of the southern peak (IJEN, Fig. 1b) and another has been installed in the NNW side of the crater (KWUI, L4 sensor, Fig. 1b). Hence, all instruments on Ijen have been monitoring seismic volcanic activity in the near field.

Seismic data from White Island have been recorded by two broadband seismic sensors (Guralp 3ESP) with a corner period of $60 \mathrm{~s}$ and are recorded on Quanterra Q330 digitizers at a rate of $100 \mathrm{~Hz}$. The stations WSRZ and WIZ are part of the New Zealand seismic network GEONET. They are located to the NNW, and within the main crater complex, respectively (Fig. $2 \mathrm{~b}$ ). The permanent stations are joined by two Trillium $120 \mathrm{~s}$ broadband seismometers (WI03 and WI04) that are recorded on Taurus digitizers at a sample rate of $100 \mathrm{~Hz}$.

The seismic processing has been carried out using two different software packages, Obspy (Krischer et al. 2015) and PITSA (Scherbaum et al. 1992), to ensure robustness 


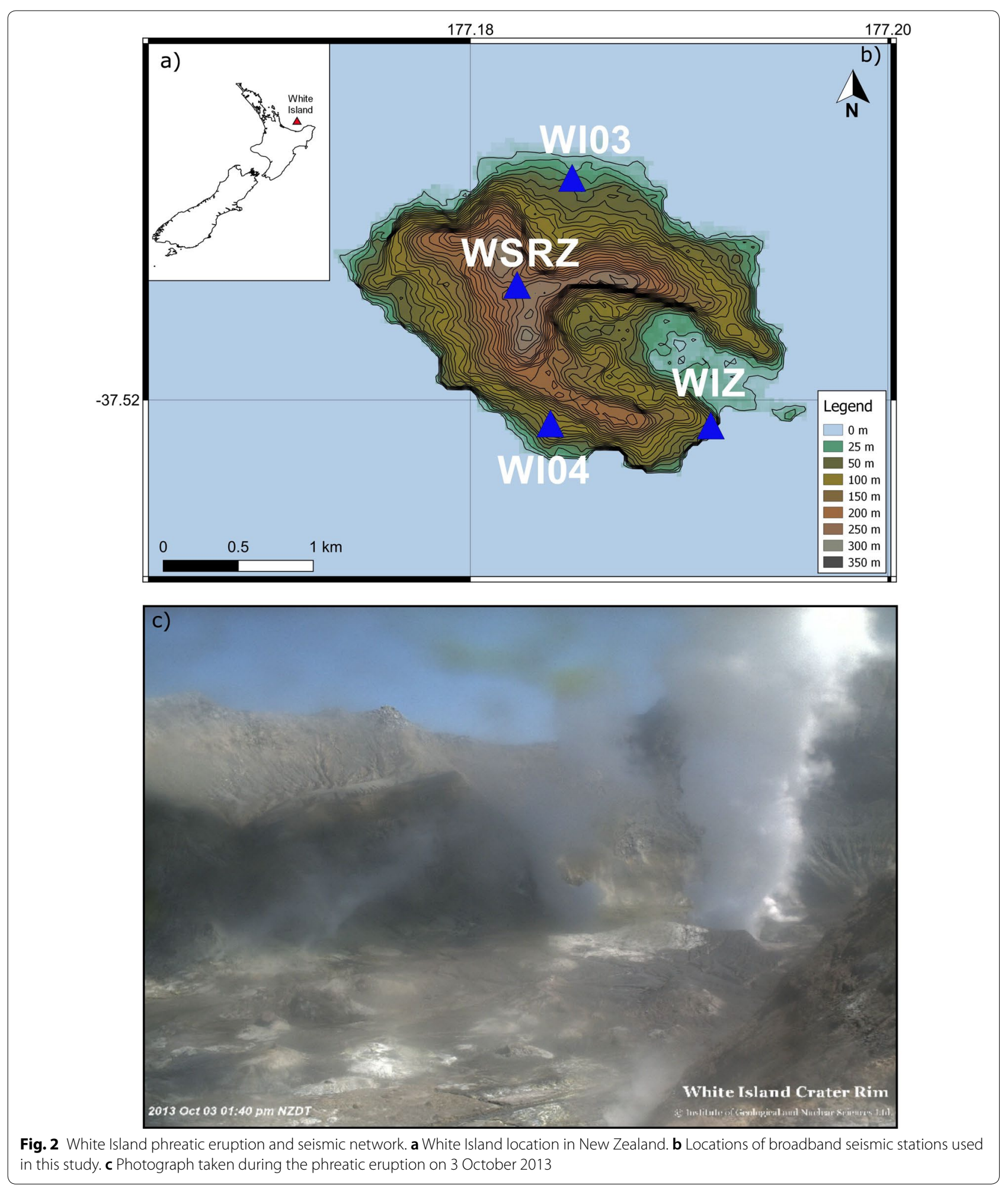

of results. Both seismic datasets have been detrended and high-pass-filtered above $0.001 \mathrm{~Hz}$ before removing the instrument response. The application of the high-pass filter prevents numerical and instrumental noise to be amplified. The signals have then been integrated to convert the velocity seismograms to displacement, and have 
been further filtered depending on the frequency band of interest.

\section{Seismic data}

\section{Kawah ljen seismicity}

The increase in volcanic activity on March 20, 2013 at Kawah Ijen was characterized by an unprecedented seismic sequence reflecting an interplay between different physical sources. A succession of high-frequency bursts (HF, 1-20 Hz, Additional file 1: Fig. A.1) of variable durations between 3 and 10 min are clearly visible in the unfiltered velocity seismograms (Fig. 3a, b). The horizontal components of the broadband sensors simultaneously recorded ultra-long-period oscillations (ULP) with dominant periods of 12-18 min embedding these HF bursts (Fig. 3d).
It is remarkable that the ULP signals seen in both horizontal components are not visible on the vertical component (Fig. 3c). This points to the generation by tilt since the horizontal components of broadband instruments are more susceptible to tilt than the vertical component. Gravity accelerates the seismometer mass in the downdip direction, if the instrument is tilted. Hence, tilt dominates over horizontal translation at periods below the seismometer's corner frequency (Wielandt and Forbriger 1999; Lyons et al. 2012).

Three VLP signals with dominant periods around $8 \mathrm{~s}$ and superimposed low-amplitude shorter oscillations (down to $1 \mathrm{~s}$, Fig. 4c, d) have also been recorded during the eruption, with the first VLP actually initiating this seismic sequence. Another set of signals, which systematically and directly followed the VLPs, is visible in the displacement records only, i.e., after data processing (red window in Fig. 4a). These oscillations last for up
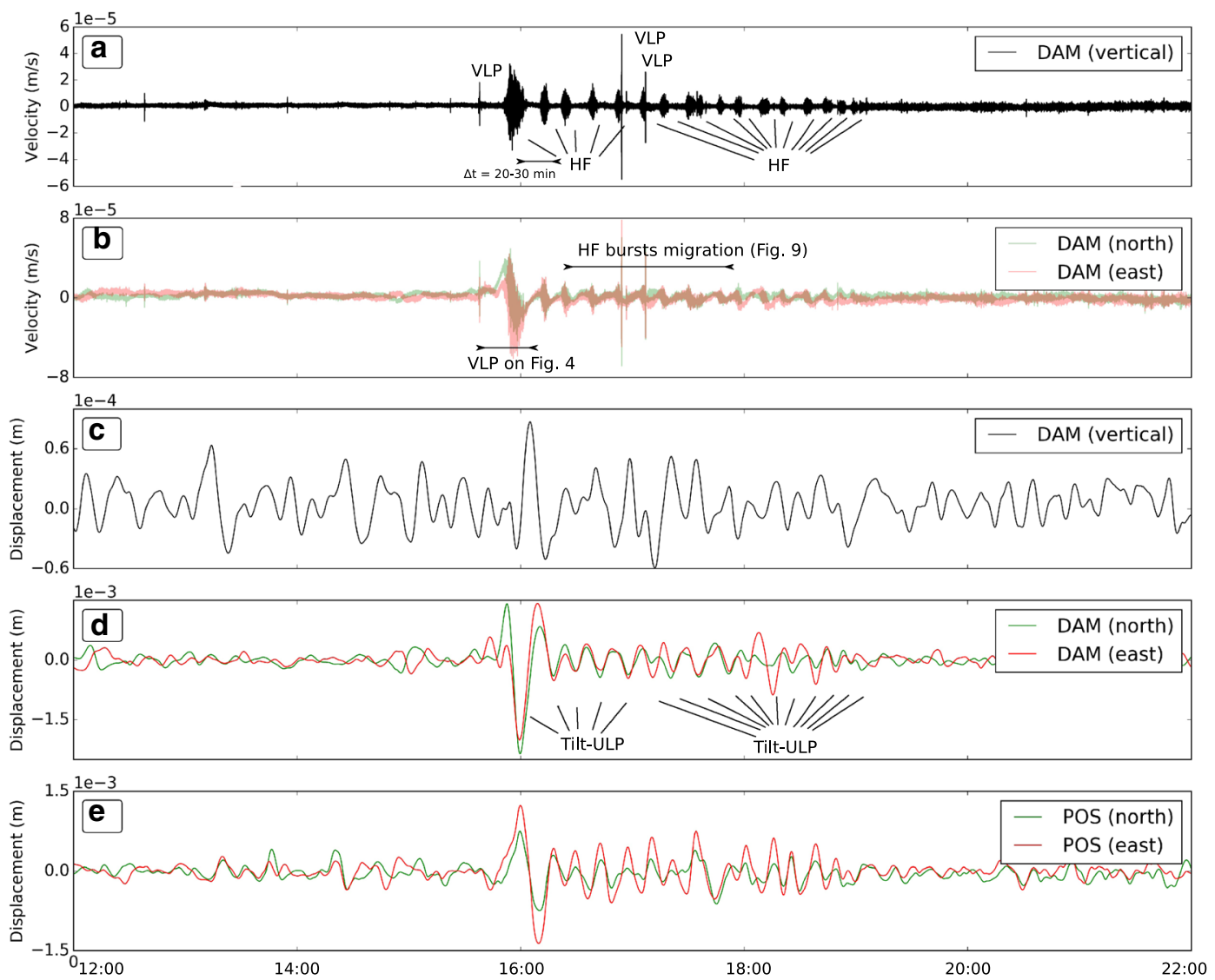

Fig. 3 Ten-hour seismograms at Kawah ljen. a Vertical velocity (station DAM). b Horizontal velocity (station DAM). c Vertical displacement (station DAM). $\mathbf{d}$ Horizontal displacement (station DAM). e Horizontal displacement (station POS). For $\mathbf{a}$ and $\mathbf{b}$, instrument responses are deconvolved after detrending and high-pass filtering the data above $0.001 \mathrm{~Hz}$. The resulting ground velocity is further integrated, detrended and band-passed between 1000 and $250 \mathrm{~s}$ to produce $\mathbf{c}-\mathbf{e}$. The dominant period of VLP signals is $8 \mathrm{~s}$ with superimposed low-amplitude shorter oscillations (down to $1 \mathrm{~s}$ period) while the HF bursts show broadband spectra with oscillations between 1 and $20 \mathrm{~Hz}$. The dominant period of the ULP tilt signals in (d) are oscillating between 12 and 18 min. Note that the vertical component in (c) is about 20 times smaller than horizontal components in (d) and can be barely distinguished from the background noise 


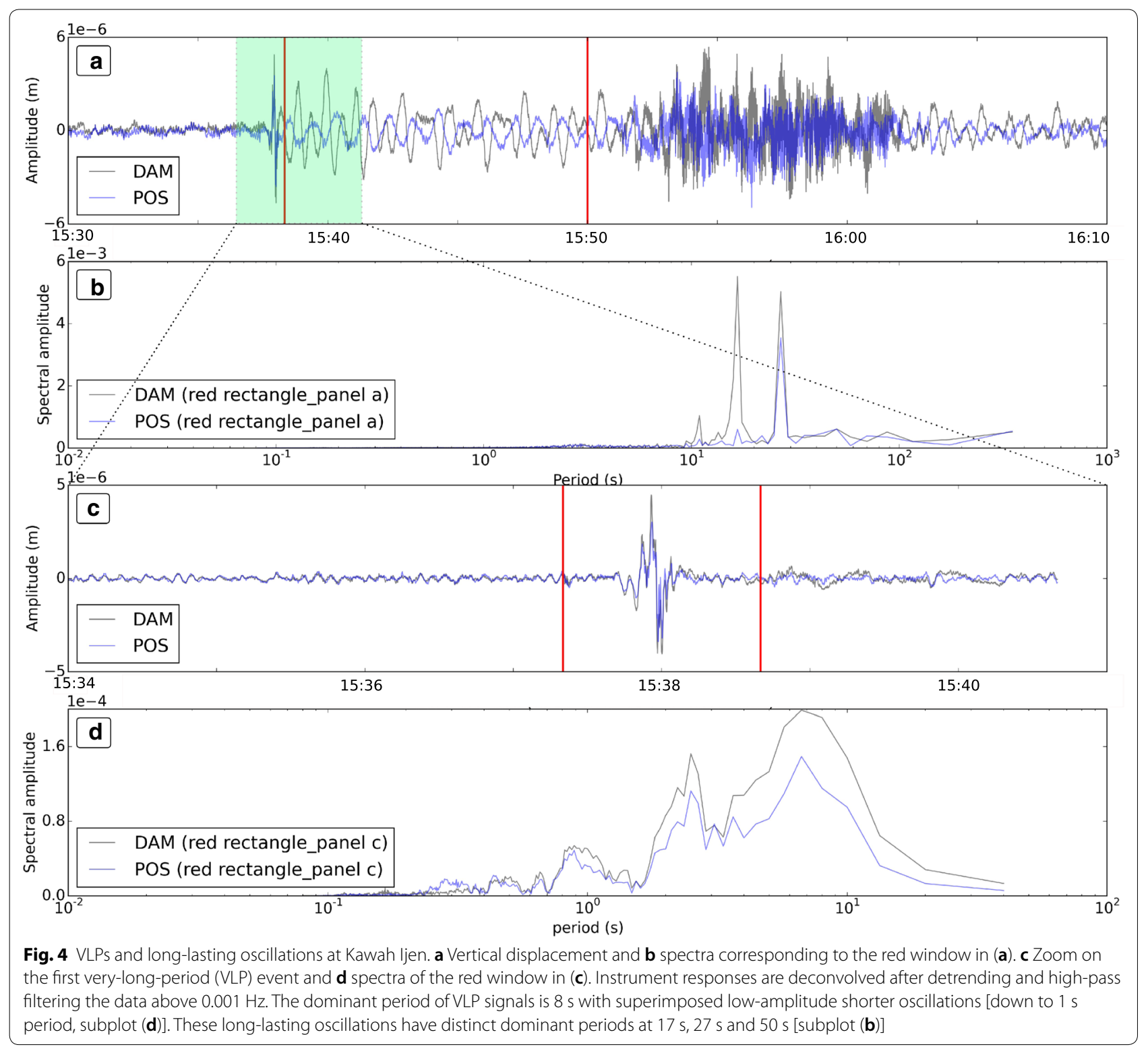

to $15 \mathrm{~min}$ and have distinct dominant periods at $17 \mathrm{~s}$ and $27 \mathrm{~s}$, and less clearly at $50 \mathrm{~s}$ (Fig. 4b). They are only captured by the broadband sensors, and most clearly at the station DAM which is located closest to the center of the phreatic activity (Fig. 1b). It is noteworthy that the maxima and minima of the displacement signals are not in phase at the different seismic stations (Fig. 4a). The data are high-pass filtered above the corner frequency of the sensors (i.e., $0.0833 \mathrm{~Hz}$ or $120 \mathrm{~s}$ period) to avoid any contamination from the ULP tilt previously described. These oscillations are detected on all seismic components; hence, VLPs and these induced long-lasting oscillations seem to occur independently from the tilt and HF bursts.

\section{White Island seismicity}

For White Island we focus on $10 \mathrm{~h}$ of seismic data recorded on October 3, 2013, during increased hydrothermal activity (Fig. 5). The episode commenced, similar to Kawah Ijen, with a VLP (03:35 UTC) followed by a series of high-frequency bursts corresponding to a small steam eruption sequence lasting for several minutes. After a short seismic quiescence of about $20 \mathrm{~min}$ continuous tremor dominated the seismicity for about 8 h. The spectral lines in Fig. 6 indicate a highly periodic excitation of the same source signal for about $8 \mathrm{~h}$ (Hammer and Neuberg 2009). The fundamental frequency evolves from $\sim 0.8 \mathrm{~Hz}$ at the onset of the tremor to $\sim 1 \mathrm{~Hz}$ when it ends. The frequency of $\sim 0.8 \mathrm{~Hz}$ implies a source 

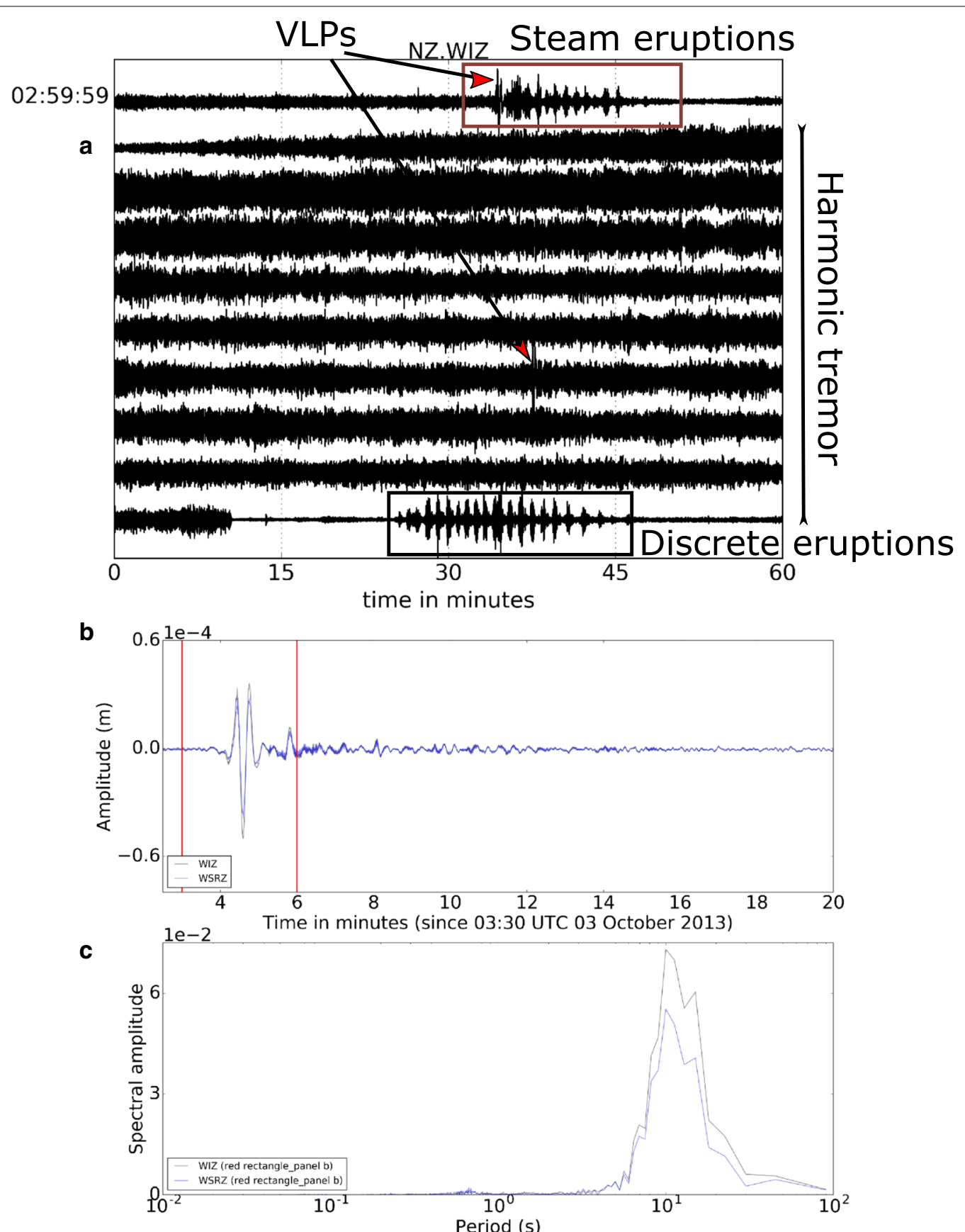

Fig. 5 Seismicity and VLPS recorded at White Island. a Vertical velocity seismogram $\mathbf{b}$ displacement corresponding to the red rectangle in a $\mathbf{c}$ spectrum corresponding to the red rectangle in b, after removing the offset, the trend and high-pass filtering below 100 s. The steam eruption was observed visually on the GeoNet Web Camera system while late stage discrete eruptions have seismo-acoustic signatures similar to small scale mud eruptions occurring in early 2013 (Jolly et al. 2016). VLPs have a dominant period of $\sim 10$ s [subplot (c)]

excitation of $\sim 1.3 \mathrm{~s}$. The strictly parallel spectral lines in Fig. 6 are also volcanic in origin, but may include significant path and site effects which tend to obscure the original source spectral features (see Additional file 1: Fig. S1). The VLP that initiated the seismic sequence was followed by another VLP after about $7 \mathrm{~h}$, completely embedded in the tremor sequence. Both VLPs have a dominant period of $\sim 10 \mathrm{~s}$ (Fig. 5), well below the seismometer's corner period of $60 \mathrm{~s}$, and therefore not affected by the instrument response. The pulsatory activity at the end of the 


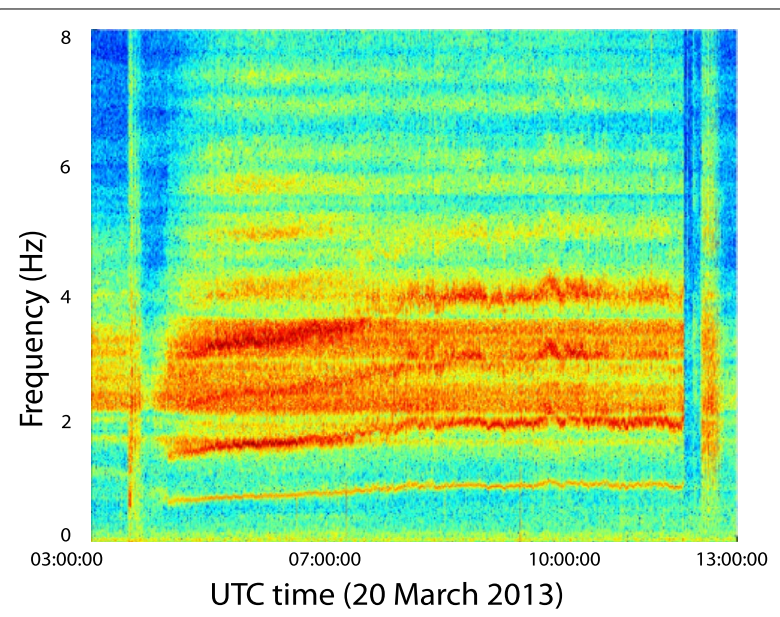

Fig. 6 Harmonic Tremor at White Island. Harmonic tremor recorded at White Island after a seismic quiescence of $20 \mathrm{~min}$, and lasting for $8 \mathrm{~h}$. The fundamental frequency evolves from $\sim 0.8$ at the onset of the tremor to $\sim 1 \mathrm{~Hz}$ when it ends. The frequency of $\sim 0.8 \mathrm{~Hz}$ implies a source excitation of $\sim 1.3 \mathrm{~s}$. We used a window of 512 samples with a 25-sample overlap to create the spectrogram

sequence corresponds to 4 eruptions recorded by the acoustic network (12:26:28, 12:27:11, 12:35:28, 12:39:31), possibly similar to the mud eruptions described in Jolly et al. (2016).

\section{VLP source locations}

To constrain their origin, VLP source locations can be determined using particle motions (e.g., Kawakatsu et al. 2000; Neuberg and Pointer 2000). By measuring the backazimuths at each station, the epicenter is determined by their intercept. After rotating the north- and east-components into radial and transverse, the radial component can be used together with the vertical component to constrain the source depth. A correction has been applied to account for the free-surface and topographical effects (Neuberg and Pointer 2000), using a $\mathrm{V}_{P} / \mathrm{V}_{S}$ ratio of 1.7 (Caudron et al. 2015b). Results for the three VLPs recorded at Kawah Ijen are consistent with each other and define a source region located $700 \pm 200 \mathrm{~m}$ below the bottom of the lake (Fig. 7b). The back-azimuths point toward the epicenter at the SW side of the crater lake (Fig. 7a). Furthermore, the first motion is pointing outward from the crater toward the W at station DAM and $\mathrm{NE}$ at station POS, suggesting an inflating source, followed by a deflation.

The first VLP is located using the aforementioned particle motion technique corrected for free-surface and topographical effects. The epicenter is SE of the crater lake, while the hypocenter has been estimated at $970 \mathrm{~m}$ below sea level (Fig. 7c, d). The classic waveform semblance (Kawakatsu et al. 2000), using the same parameters as in Jolly et al. (2017), was also applied and gave a similar location (depth errors 700-1000 m, based on 2\% error limit from maximum semblance, $100 \mathrm{~m}$ semblance grid). The semblance (0.8375) and signal-to-noise ratio (9.9255) are particularly high compared to the VLPs analyzed by Jolly et al. (2017), indicating reliable locations. The second VLP was also located in same area (within errors), but the semblance $(0.6408)$ and SNR (5.8669) were much lower. Compared to Jolly et al. (2017)'s study, lower frequency limits were used due to the extended sensitivity of WI03-WI04 at long period (dominant period of $120 \mathrm{~s}$ ).

\section{Discussion}

Several additional parameters have been measured during the phreatic eruption at Kawah Ijen. A sudden volcanic lake temperature increase has been recorded on 20 March coincident with the apparent lake level increase and explosions that caused the sulfur miners to leave. The lake volume increased by 1.38 million $\mathrm{m}^{3}$ between 17 March and 18 April and the lake water temperature culminated to $59{ }^{\circ} \mathrm{C}$ a week after the eruption. Such lake volume and temperature increases are highly unusual; the lake volume typically increasing by 3 million $\mathrm{m}^{3}$ during the entire rainy season and the lake temperature rarely exceeding $50{ }^{\circ} \mathrm{C}$ (Caudron et al. 2015a). The photos taken on 27 March show that the whole white lake surface was evaporating. A physical interaction between magma and water would likely trigger explosions at the surface and decrease the lake volume through vaporization as it has been observed for example during the 2007 eruption at Kelud volcano (Caudron et al. 2012). This phreatic eruption may therefore be characterized by a sudden input of hydrothermal fluids without any direct magma interaction with the lake.

In the following, we interpret the HF bursts and tilt as well as the VLPs and the long-lasting oscillations separately.

\section{Mechanisms for VLPs and long-lasting oscillations}

We first investigate the possible mechanisms that could generate VLP events (Fig. 4c). VLPs are rarely recorded at these volcanoes and seem to trigger long-lasting oscillations in the Kawah Ijen volcanic lake. Since no magma reached the surface, the most likely source mechanisms lie in the hydrothermal reservoir. At Ruapehu volcano (New Zealand), (Jolly et al. 2010) observed VLP pulses at $3-7 \mathrm{~km}$ depth prior to the phreatic eruption associated with volumetric contraction probably due to fluid migration, followed by VLP signals linked with material emission. At Ontake (Japan), a VLP located at a depth of 300-1000 m below the eruptive vents preceded the 2014 phreatic eruption by $25 \mathrm{~s}$ (Maeda et al. 2015a). A subvertical tensile crack may have opened due to ascending 


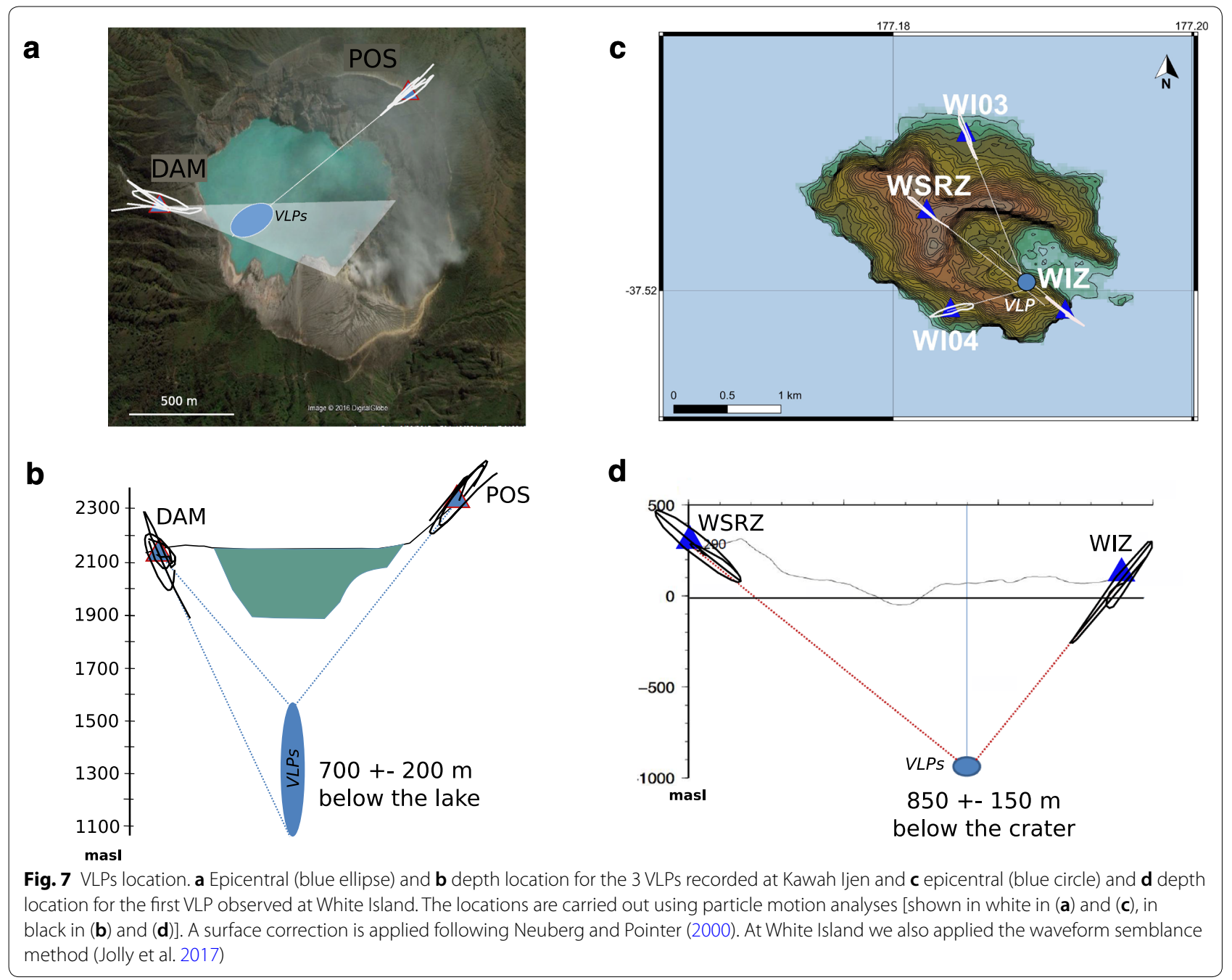

gas that eventually triggered the eruption (Maeda et al. 2015a). At Mayon volcano (Philippines), (Maeda et al. 2015b) ascribed a VLP recorded during the eruption to boiling of underground water in a shallow and subhorizontal tensile crack producing inflation followed by a deflation during discharge of water vapor. At Aso volcano (Japan), (Kawakatsu et al. 2000) interpreted the VLP source as caused by activity in a hydrothermal reservoir induced by hot gases leaking from a deep-seated magma chamber. The shallow crack (1-1.5 km beneath the crater) inflates prior to an eruption and deflates during the discharging stage. At Satsuma-Iwojima volcano (Japan), (Ohminato 2006) involved a water-filled crack connected to a network of gas pockets separated by narrow constricted pathways. Using a dense seismic deployment at Asama (Japan), (Maeda and Takeo 2011) linked VLP events to an influx of gas into a shallow cavity. In conclusion, as recently highlighted by Stix and Moor (2018), VLP signals appear to be reliable indicators of pressurization of the shallow hydrothermal system, although the timescales of pressurization may be variable.

It is worth highlighting the remarkable agreement between our VLP source location at White Island and Jolly et al. (2017)'s ones in 2011 during a sequence of VLP. The depths for VLPs at Kawah Ijen interestingly fall in the same range, i.e., 700-900 m. Jolly et al. (2017) ascribed VLPs to repeating excitations of a stationary crack above a shallow magma storage region during strong gas flux periods. Gas escape where the magma column convection ceases; conductive heat losses leading to crystallization of microlites and consequent increasing viscosity (Stevenson and Blake 1998). The gas can be trapped behind a ductile carapace and, hence, accumulate, until enough gas pressure is achieved to break through the carapace (Jolly et al. 2017). This ductile carapace behaves as an impermeable shell and would correspond to zones of hot and weak rock with strong $\mathrm{V}_{p}$ 
$/ \mathrm{V}_{s}$ contrasts (and high poisson ratios) (Dawson et al. 1999). The failure of a magma carapace due to the release of fluids acts as the source of VLP; the high waveform coherence between individual VLPs in Jolly et al. (2017) indicating the repeating nature of such process. The crack generally releases gases passively, but during periods of high flux, the gas would produce discrete VLPs (Jolly et al. 2017). Under low flux conditions, the magma carapace may have sufficient permeability to allow unhindered gas migration to shallower depth. A large gas pulse, however, may exceed the confining pressure of the carapace and promote rupture within VLP source frequencies. Such conceptual model appears viable and could explain the triggering of VLPs at both volcanoes.

What happens in the aftermath appears crucial to understand the generation of phreatic eruptions. VLPs may influence the shallow hydrothermal system in different ways. They may impart both rapid stress pulses and mass pulses. The long-lasting signals at Kawah Ijen directly follow VLPs (Fig. 4). Modeled migration rates for gas ascent in a single-phase gas system suggest time lags from $30 \mathrm{~min}$ to $2 \mathrm{~h}$ at the given VLP depth (O'Brien and Bean 2008). Such rates are too slow to instantaneously trigger long-lasting oscillations at Kawah Ijen, leaving us with stress change as the most plausible mechanism. The attendant mass pulses could later affect the system, e.g., through the generation of HF bursts.

We next interpret these long-lasting oscillations as caused by a so-called seiche (Fig. 4a). A seiche is an eigenoscillation or resonance of an enclosed body (Aster et al. 2003) of water caused by the flexure of the solid Earth in response to a standing water wave (McNamara et al. 2011), hence in our case the resonance of a crater lake, triggered by the phreatic explosion and represented by the VLP. The period of a seiche, $T$, is linked to the dimensions of an irregular basin in which it takes place and is expressed by the Merian's formula (Merian 1828):

$$
T=\frac{2 L}{n \sqrt{g h}}
$$

where $L$ is the length of the basin, $h$ is the mean depth of the basin and $g$ is the acceleration due to gravity $(g \sim 9.81$ $\mathrm{m} / \mathrm{s}^{2}$ ). For $n=1, T$ is the period of the fundamental mode, while $n=2,3, \ldots$ denote higher harmonics.

Using the dominant periods of the oscillations recorded at the broadband stations POS and DAM, $T=27 \mathrm{~s}$ and $50 \mathrm{~s}$ and assuming a mean depth of the lake of $h=90 \mathrm{~m}$, derived from bathymetric measurements (Caudron et al. 2015a), we find dimensions $L$ for the lake of $\sim 400 \mathrm{~m}$ and $\sim 740 \mathrm{~m}$ which is in reasonable agreement with the average width and length of the crater lake, respectively. The period of $17 \mathrm{~s}$ can be interpreted as the third overtone of the length of the lake which is observed at the station DAM, while the station POS is dominated by the second overtone (27 s) that corresponds to the NNW-SSE width of the crater lake (Fig. 1a). The absence of a seiche signal following the VLPs at White Island is easily explained by the fact that White Island's crater lake is too shallow to develop a resonance.

\section{Mechanisms for high-frequency bursts at Kawah ljen}

A last observation comes from the analysis of amplitude ratios at Kawah Ijen. Following Taisne et al. (2011), amplitude ratios across the four seismic stations of Kawah Ijen were computed in the $5-15 \mathrm{~Hz}$ band (Fig. 8 and "Appendix"). Temporal changes of amplitude ratios can be due to a change in the attenuation or velocity of seismic waves or to a change in source location. At the timescale of a few hours, the change in source location is favoured. Due to the relatively high frequency, and the scattering of the medium, the source is assumed to be isotropic (Taisne et al. 2011; Morioka et al. 2017; Caudron et al. 2018). We only consider two types of migration: a vertical and a lateral migrating source. A downward migration of seismic source has only been observed prior to the 2014 Ontake eruption (Ogiso et al. 2015) and is therefore considered as less plausible. The consistent change in ratios across the network between 16:00 (UTC) and 17:00 (UTC) is therefore ascribed to a lateral or upward source migration (Fig. 9).

Without locating the source itself, we can still estimate where the migration occurred. For example, the increase in IJEN/POS ratio indicates a source progressively moving close to IJEN than POS. Assuming a vertical upward migration of the seismic source, an increase in the IJEN/ POS ratio could be explained by a source located to the south of the equal-distance line between the IJEN and POS stations. This approach is applied to the different pairs of stations to constrain the possible location at the surface. With the additional assumption for the lateral migration that the migration occurs within the region defined by the network. A level of confidence (ranging between 5 and 20) is assigned to each region defined by the equal-distance line for a station pair based on a qualitative estimate of the steps in amplitude ratio. The most probable area extracted from this qualitative analysis corresponds to the whitest polygon in Fig. 9. This migration is interpreted as a vertical fluid injection that generated micro-fracturing in the shallow volcanic-hydrothermal system or as a progressive lateral rupture of a seal located below the lake bottom.

HF bursts were accompanied by ULP signals on horizontal components. At Aso volcano, Japan, ultra-longperiod ( $>100 \mathrm{~s}$ ) displacements, recorded on vertical and horizontal channels, often preceded eruptions by a few 


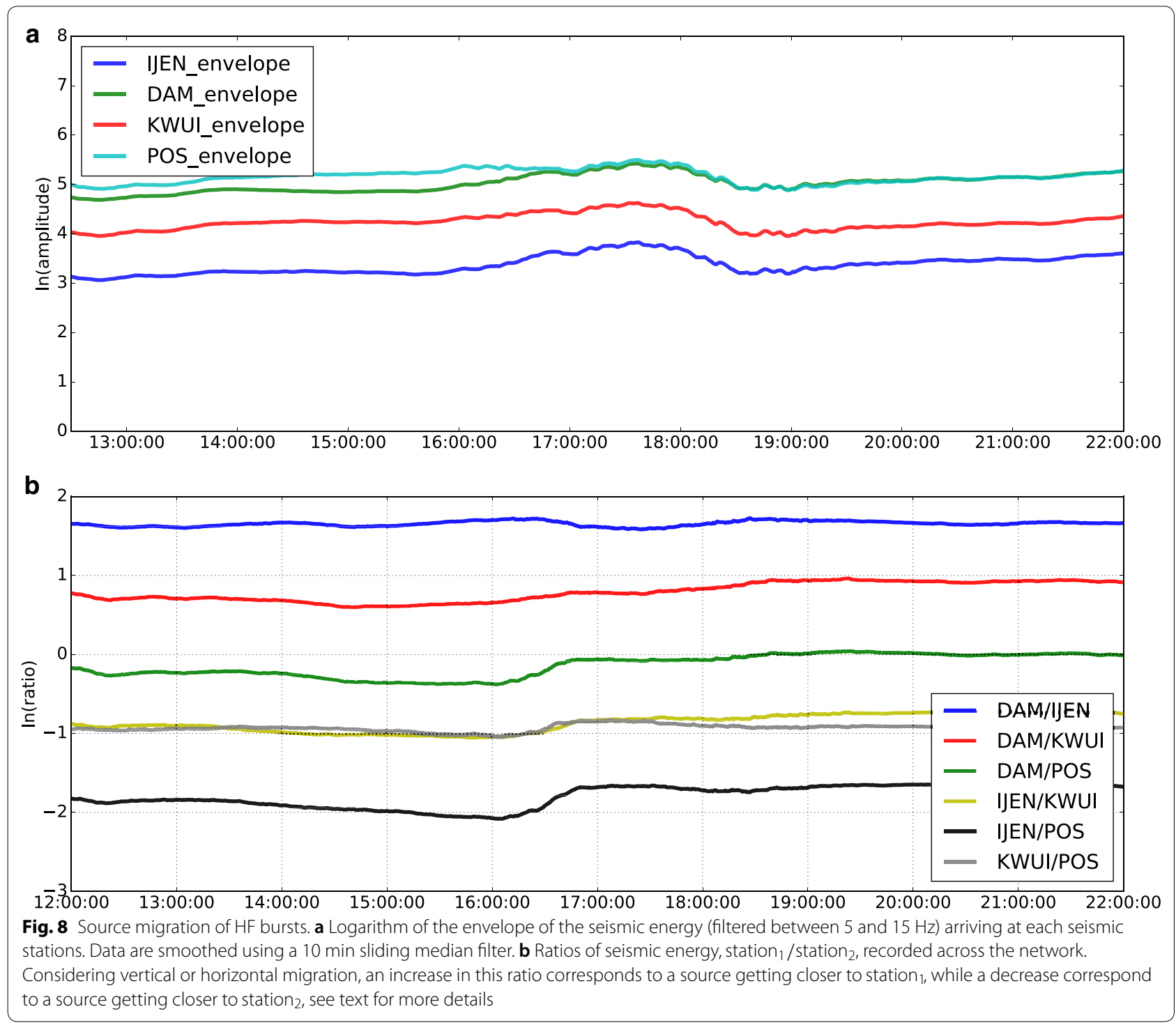

minutes, which Kawakatsu et al. (2000) attributed to a gradual increase in fluid pressure. Vandemeulebrouck et al. (2014) hypothesized that the $\sim 4$ min period ULPs recorded at Lone Star Geyser (USA) are generated by the slow ascent of vapor slugs that appear to behave independently from geyser eruption cycle. It is difficult to constrain the origin of the ULP tilt signal at Kawah Ijen with only two broadband sensors.

We noted that the first HF burst at Kawah Ijen only occurred $\sim 15$ min after the first VLP. This delay time may be a key feature of this sequence and will help us to explore the mechanism that generates such HF bursts. HF bursts are interpreted as gas slugs rather than stress changes since the modeled migration rates [O'Brien and Bean (2008) and discussion above] are relatively consistent with our observations. HF bursts could reflect the response of the shallow hydrothermal system to mass pulses transferred from VLP depths. The shallow tremor would represent the failure of a shallow seal located at the bottom of the lake. The development of shallow seals, formed by the precipitation of sulfur, has been proposed at White Island (Christenson et al. 2017). Likewise, the development of a sulfur seal appears likely at Kawah Ijen (Takano et al. 2004).

A rapid temperature or pressure change may perturb a system beyond a metastable state and force it into an unstable state resulting in a spontaneous and explosive phase separation. This is sometimes referred to as spinodal decompositions and occurs throughout the fluid (e.g., Favvas and Mitropoulos 2008; Thiéry and Mercury 2009a). Therefore, a liquid heated rapidly into a metastable state (Ohminato 2006) would generate a particularly 


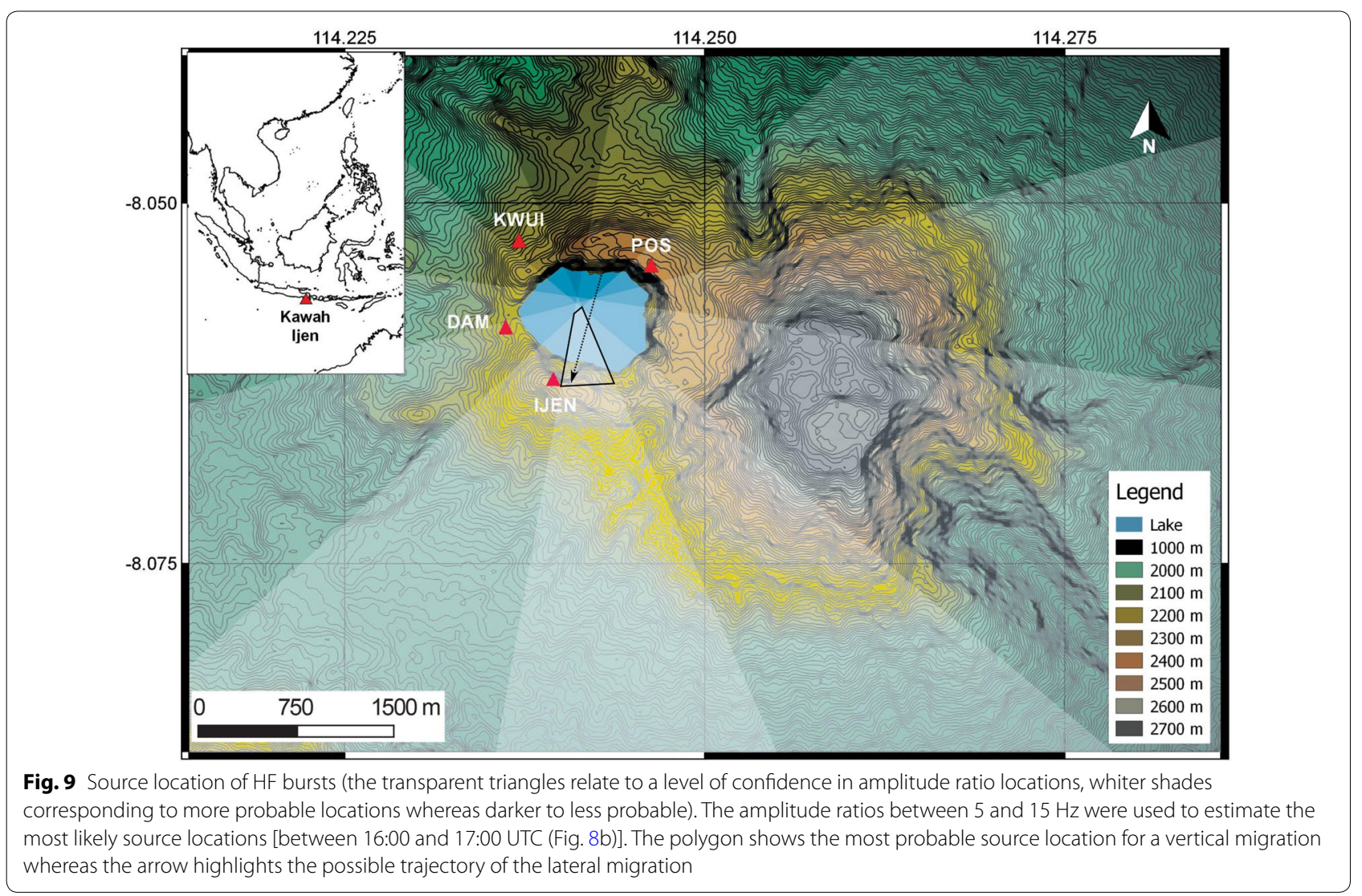

violent explosion if it crosses the liquid spinodal line (Fig. 10a, b). At the bottom of Kawah Ijen volcanic lake, pressures are close to $2 \mathrm{MPa}$ and temperatures around $200^{\circ} \mathrm{C}$ (Caudron et al. 2015b), while temperatures are $>119^{\circ} \mathrm{C}$ and pressures do not exceed $\sim 1 \mathrm{MPa}$ at White Island (Christenson et al. 2017). Although these conditions would not allow violent liquid-to-gas phase changes in a pure water-water system at Kawah Ijen (light blue rectangle in Fig. 10a), a binary $\mathrm{H}_{2} \mathrm{O}-\mathrm{CO}_{2}$ system would allow for rapid phase changes, i.e., the liquid spinodal line shifts to lower temperatures (orange dashed curves in Fig. 10b). Significant amounts of $\mathrm{CO}_{2}$ have been measured within the Kawah Ijen lake (Caudron et al. 2016), whereas significant $\mathrm{CO}_{2}$ concentrations with mole fractions of $\mathrm{CO}_{2}$ higher than 0.12 at White Island (Werner et al. 2008). Hence, at both volcanoes, failure of a seal could reflect the response of the shallow system due to mass transfer induced by VLPs that would tens of minutes later trigger sudden phase changes. This could be consistent with the explosions heard by the sulfur miners at Kawah Ijen, while they were working in the crater.

\section{Source mechanism for harmonic tremor at White Island}

The most remarkable feature in the 8-h tremor sequence on White Island is the highly periodic excitation mechanism (Neuberg et al. 2006) acting every 1.0-1.3 s (at its onset and at its end, respectively) which is likely a source effect since it is observed at both stations at exactly the same frequencies. Furthermore, these lines in the spectrogram suggest a repetitive, identical source mechanism at the same source position. A migrating source, as in the case of Kawah Ijen, would produce waveforms evolving with time, prohibiting the generation of sharp lines in the spectrogram. Taken these observations together, we assume a highly periodic source mechanism at a fixed source location over at least $8 \mathrm{~h}$. Such a source mechanism rules out any brittle failure of rock within the volcanic edifice, but points to the generation of pressure pulses within fluid flow. So-called eddy-shedding (Julian 1994) when fast flowing hydrothermal fluids squeeze through obstructions in their pathways could be one mechanism that could explain the observed features of the tremor signature. An alternative mechanism has also been proposed for dome building eruptive settings and consists of the brittle failure of viscous magma in glass transition (Neuberg et al. 2006; Collier and Neuberg 2006). If the shear stress at specific locations in the volcanic plumbing system exceeds the threshold of yield strength of the magma, brittle failure in the melt phase will occur. However, it is uncertain if the magma system 

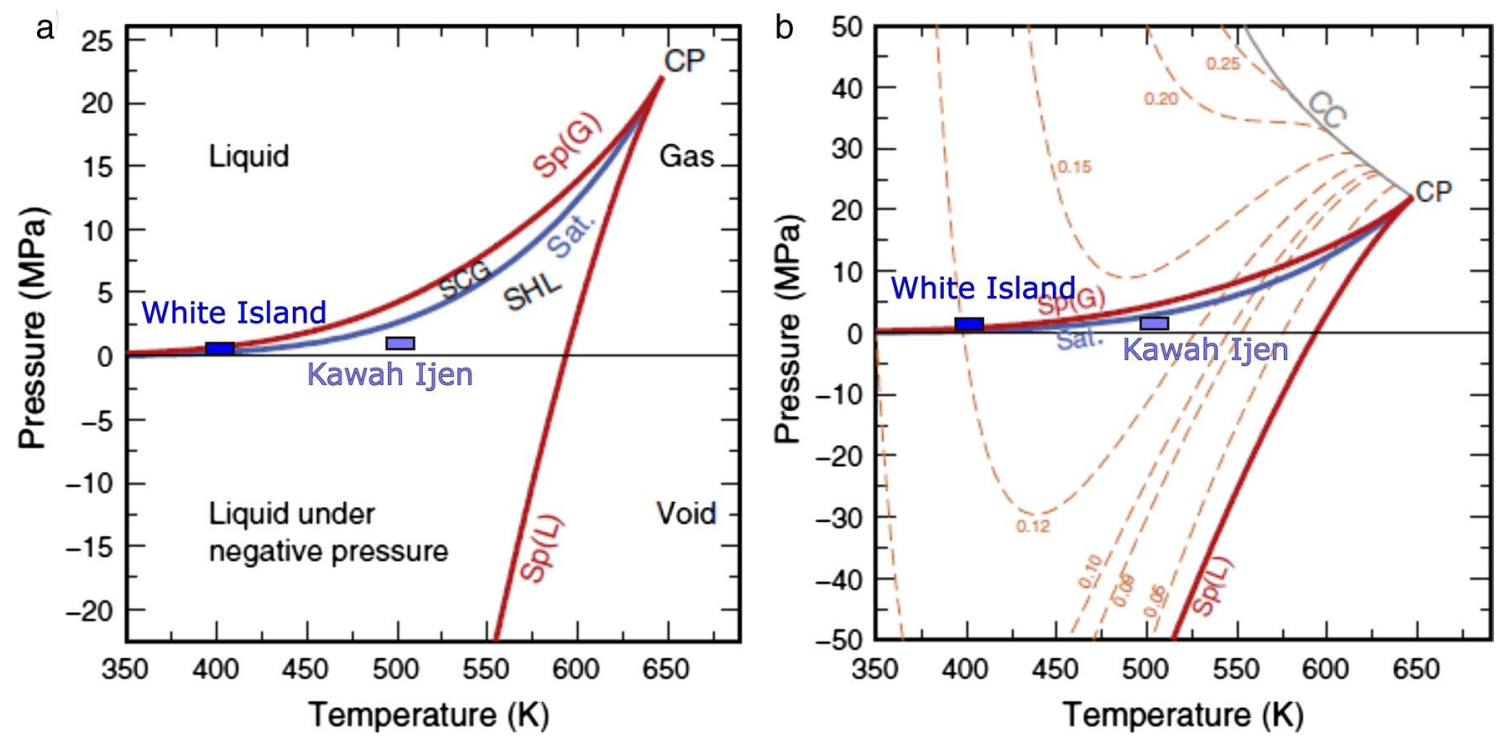

Fig. 10 Phase diagrams Stable, metastable, and unstable regions in P-T space according to IAPWS-95 equation of state of water (Wagner and Pruß 2002). In $\mathbf{a}$ and $\mathbf{b}$ the blue line is the vapor-pressure curve or saturation curve (Sat.) while the red line are the spinodals. Sp(G) is the gas spinodal, $\mathrm{Sp}(\mathrm{L})$ is the liquid spinodal. The three lines meet at a critical point (CP). SCG denotes supercooled gas, while SHL denotes superheated liquid. In $\mathbf{b}$ the orange dashed curves represent the liquid spinodals for the $\mathrm{H}_{2} \mathrm{O}-\mathrm{CO}_{2}$ critical curve (CC). The light and dark blue rectangles correspond to P-T conditions beneath the presumed seal regions at Kawah ljen (Caudron et al. 2015b) and White Island (Christenson et al. 2017), respectively. After Thiéry and Mercury (2009a), Thiéry and Mercury (2009b) and modified from Matoza and Chouet (2010), Chouet and Matoza (2013)

inferred for White Island (e.g., Cole et al. 2000) is capable of producing magmatic failure in the glass transition as described here. At the Earths' surface, non-periodic excitations due to gas slugs, have been shown to produce spectral signals that have harmonic characteristics and may relate to energy burst dynamics of the slug (Jolly et al. 2016). In the present case, the gliding spectral lines imply instead a systematically evolving repeated triggering that more likely related to constricted flow within the shallow hydrothermal system".

\section{Conclusions}

In this study, we explore with mainly seismological means phreatic eruptions and the hydrothermal systems responses at two similar volcanoes, Kawah Ijen, Indonesia and White Island, New Zealand. We focus on periods of phreatic eruptions which are currently not fully understood, but pose, nevertheless, a considerable volcanic hazard claiming time and again some human lives. By carefully processing broadband seismic signals, we disclose seismic signatures and characteristics often buried in unprocessed velocity seismograms. These signals shed light on several aspects of phreatic eruptions, their generation and timeline.

On both volcanoes, Kawah Ijen and White Island, the phreatic eruptions are initiated with a VLP, followed by further VLP activity. Using seismic particle motion analysis, these events are located at depths between 700 and $900 \mathrm{~m}$ below the crater region. Given this depth and the corresponding pressure, we suggest a trigger mechanism that is induced by release of gas trapped behind a ductile magma carapace. The seismic energy released subsequently triggers an eigen-oscillation or seiche of the crater lake at Kawah Ijen. The seismicity exhibits long-lasting, long-period oscillations with characteristic periods that can be linked to the dimensions of the crater lake. Subsequent high-frequency bursts superimposed to tilt signals suggest further fluid migration and corresponding changes in the shallow hydrothermal system, either associated with the lateral rupture of a seal or the rise of fluids to the SW of the crater lake. While the migration manifests itself $\sim 15$ min later as migrating high-frequency tremor at Kawah Ijen, harmonic tremor is recorded $\sim 25 \mathrm{~min}$ after the VLP at White Island and occurs at a fixed location possibly generated by pressure pulses within fluid flow. Overall, most of the seismic signals described and analyzed here were not captured by short-period seismometers. This fact further emphasizes the need to deploy broadband seismic equipment close to active volcanic activity. 


\section{Additional file}

Additional file 1. Spectrograms of harmonic tremor at White Island. Harmonic tremor recorded at White Island after a seismic quiescence of 20 min, and lasting for $8 \mathrm{~h}$. a station WIZ $\mathbf{b}$ stations WSRZ. We used a window of 20 s without any overlap to create the spectrograms.

\section{Authors' contributions}

CC, BT, JN, AJ and TL analyzed the seismic data. CC, BT, JN, AJ and BC wrote the manuscript. $B C$ and JN provided insights into the interpretation of the VLP triggering at White Island. CC, BT, JN, AJ and BC interpreted the results. CC, AJ, $\mathrm{TL}, \mathrm{S}, \mathrm{DS}$ and GS collected the seismic data and maintained the seismic stations. All authors read and approved the final manuscript.

\section{Author details}

${ }^{1}$ Earth Observatory of Singapore, Nanyang Technological University, 50 Nanyang Avenue, Block N2-01a-15, Singapore 639798, Singapore. ${ }^{2}$ G-time, Université Libre de Bruxelles, Avenue Franklin Roosevelt 50, 1050 Brussels, Belgium.

${ }^{3}$ Royal Observatory of Belgium, Avenue Circulaire 3, 1180 Uccle, Belgium. ${ }^{4}$ Department of Geology, Ghent University, Campus Sterre, S8, Krijgslaan 281, 9000 Ghent, Belgium. ${ }^{5}$ Asian School of the Environment, Nanyang Technological University, 50 Nanyang Avenue, Block N2-01a-15, Singapore 639798, Singapore. ${ }^{6}$ School of Earth and Environment, The University of Leeds, Leeds LS2 9JT, UK. ${ }^{7}$ GNS Science, Wairakei Research Centre, Taupo, New Zealand. ${ }^{8}$ Center for Volcanology and Geological Hazard Mitigation, Bandung, Indonesia.

\section{Acknowledgements}

The authors thank both reviewers and the editor for their insightful comments and suggestions that greatly improved this study. Seaborn and Matplotlib (Hunter 2007) python packages were used to generate the figures and Obspy (Krischer et al. 2015) to analyze seismic data. The MSNoise software is available from http://msnoise.org/doc/. We thank Yves Descatoires for his help to construct the Fig. 10. We also thank Ivan Lokmer for his insightful comments and questions on an earlier version of this paper. C. Caudron benefited from a FNRS Chargé de Recherche postdoctoral grant. This work comprises Earth Observatory of Singapore Contribution No. 212. This research is partly supported by the National Research Foundation Singapore and the Singapore Ministry of Education under the Research Centres of Excellence initiative.

\section{Competing interest}

The authors declare that they have no competing interests.

\section{Availability of data and materials}

The Kawah ljen data used and analyzed during the current study are available from the corresponding author on reasonable request. The White Island data are publicly available and have been downloaded from GeoNet. We therefore acknowledge the New Zealand GeoNet project and its sponsors EQC, GNS Science and LINZ, for providing data/images used in this study.

\section{Funding}

C. Caudron was funded by a FNRS Chargé de Recherche Grant in 2016-2017.

\section{Appendix}

The amplitude ratios were computed using the MSNoise software (Lecocq et al. 2014). The raw data are detrended and cosine tapered (10\%) before being resampled from 200 to $40 \mathrm{~Hz}$. The resulting trace is filtered between 5 and $15 \mathrm{~Hz}$, and the envelope is calculated. The data are decimated to $1 \mathrm{~s}$ (using the median) and the results are finally smoothed using a 10-min rolling median. To avoid the estimate of the seismic amplitude at the source, the ratios are calculated.

$$
\ln \frac{A_{1}}{A_{2}}=n \ln \frac{r_{2}}{r_{1}}-B\left(r_{1}-r_{2}\right)
$$

with,

$$
B=\frac{\pi f}{Q \beta}
$$

where $A$ is the amplitude at stations 1 and $2, r$ is the distance between the source and stations 1 and 2 and $n=1$ for body waves and $n=0.5$ for surface waves. $\beta$ is shear wave velocity, $Q$ is the quality factor for attenuation, and $f$ is the central frequency $(10 \mathrm{~Hz})$.

Site effect, gain or sensitivity changes, shear wave velocity and attenuation are unlikely to change at the time scale of a few hours. Temporal changes of the amplitude ratios are therefore interpreted in terms of a change in the source location.

\section{Publisher's Note}

Springer Nature remains neutral with regard to jurisdictional claims in published maps and institutional affiliations.

Received: 10 April 2018 Accepted: 6 October 2018

Published online: 24 October 2018

\section{References}

Aki K, Richards PG (2002) Quantitative seismology. University Science Books, Sausalito

Aster R, Mah S, Kyle P, Mclntosh W, Dunbar N, Johnson J, Ruiz M, McNamara S (2003) Very long period oscillations of Mount Erebus Volcano. J Geophys Res Solid Earth 108(B11):2522

Barberi F, Bertagnini A, Landi P, Principe C (1992) A review on phreatic eruptions and their precursors. J Volcanol Geotherm Res 52(4):231-246

Caudron C, Mazot A, Bernard A (2012) Carbon dioxide dynamics in Kelud volcanic lake. J Geophys Res Solid Earth 117(B5):B05102

Caudron C, Syahbana DK, Lecocq T, Van Hinsberg V, McCausland W, Triantafyllou A, Camelbeeck T, Bernard A (2015a) Kawah ljen volcanic activity: a review. Bull Volcanol 77(3):1-39

Caudron C, Lecocq T, Syahbana DK, McCausland W, Watlet A, CamelbeeckT, Bernard A (2015b) Stress and mass changes at a "wet" volcano: example during the 2011-2012 volcanic unrest at Kawah Ijen volcano (Indonesia). J Geophys Res Solid Earth 120(7):5117-5134

Caudron C, Mauri G, Williams-Jones G, Lecocq T, Syahbana DK, De Plaen R, Peiffer L, Bernard A, Saracco G (2016) New insights into the Kawah Ijen hydrothermal system from geophysical data. Geol Soc Lond Spec Publ 437:437

Caudron C, Campion R, Rouwet D, Lecocq T, Capaccioni B, Syahbana D, Purwanto BH, Bernard A (2017) Stratification at the Earth's largest hyperacidic lake and its consequences. Earth Planet Sci Lett 459:28-35

Caudron C, White RS, Green RG, Woods J, Ágústsdóttir T, Donaldson C, Greenfield T, Rivalta E, Brandsdóttir B (2018) Seismic Amplitude Ratio Analysis of the 2014-15 Bárdarbunga-Holuhraun dike propagation and eruption. J Geophys Res Solid Earth 123(1):264-276

Chardot L, Jolly AD, Kennedy BM, Fournier N, Sherburn S (2015) Using volcanic tremor for eruption forecasting at White Island volcano (Whakaari), New Zealand. J Volcanol Geotherm Res 302:11-23

Chouet BA, Matoza RS (2013) A multi-decadal view of seismic methods for detecting precursors of magma movement and eruption. J Volcanol Geotherm Res 252:108-175 
Christenson B, White S, Britten K, Scott B (2017) Hydrological evolution and chemical structure of a hyper-acidic spring-lake system on Whakaari/White Island, NZ. J Volcanol Geotherm Res 346:180-211

Cole J, Thordarson T, Burt R (2000) Magma origin and evolution of White Island (Whakaari) volcano, Bay of plenty, New Zealand. J Petrol 41(6):867-895

Collier L, Neuberg J (2006) Incorporating seismic observations into 2 d conduit flow modeling. J Volcanol Geotherm Res 152(3):331-346

Dawson P, Chouet B, Okubo P, Villaseñor A, Benz H (1999) Three-dimensional velocity structure of the Kilauea Caldera, Hawaii. Geophys Res Lett 26(18):2805-2808

Favvas E, Mitropoulos AC (2008) What is spinodal decomposition. J Eng Sci Technol Rev 1:25-27

Hammer C, Neuberg JW (2009) On the dynamical behaviour of low-frequency earthquake swarms prior to a dome collapse of Soufrière Hill volcano, Montserrat. Geophys Res Lett 36(6):L06305

Hunter JD (2007) Matplotlib: a 2d graphics environment. Comput Sci Eng 9(3):90-95

Jolly A, Sherburn S, Jousset P, Kilgour G (2010) Eruption source processes derived from seismic and acoustic observations of the 25 September 2007 Ruapehu eruption-North Island, New Zealand. J Volcanol Geotherm Res 191(1):33-45

Jolly A, Kennedy B, Edwards M, Jousset P, Scheu B (2016) Infrasound tremor from bubble burst eruptions in the viscous shallow crater lake of White Island, New Zealand, and its implications for interpreting volcanic source processes. J Volcanol Geotherm Res 327:585-603

Jolly A, Lokmer I, Thun J, Salichon J, Fry B, Chardot L (2017) Insights into fluid transport mechanisms at White Island from analysis of coupled very long-period (VLP), long-period (LP) and high-frequency (HF) earthquakes. J Volcanol Geotherm Res 343:75-94

Julian BR (1994) Volcanic tremor: nonlinear excitation by fluid flow. J Geophys Res Solid Earth 99(B6):11859-11877

Kawakatsu H, Kaneshima S, Matsubayashi H, Ohminato T, Sudo Y, Tsutsui T, Uhira K, Yamasato H, Ito H, Legrand D (2000) Aso94: Aso seismic observation with broadband instruments. J Volcanol Geotherm Res 101(1):129-154

Krischer L, Megies T, Barsch R, Beyreuther M, Lecocq T, Caudron C, Wassermann J (2015) ObsPy: a bridge for seismology into the scientific Python ecosystem. Comput Sci Discov 8(1):014003

Kumagai H, Nakano M, Maeda T, Yepes H, Palacios P, Ruiz M, Arrais S, Vaca M, Molina I, Yamashima T (2010) Broadband seismic monitoring of active volcanoes using deterministic and stochastic approaches. J Geophys Res Solid Earth 115(B8):B08303

Lecocq T, Caudron C, Brenguier F (2014) Msnoise, a python package for monitoring seismic velocity changes using ambient seismic noise. Seismol Res Lett 85(3):715-726

Lokmer I, Bean CJ (2010) Properties of the near-field term and its effect on polarisation analysis and source locations of long-period (LP) and verylong-period (VLP) seismic events at volcanoes. J Volcanol Geotherm Res 192(1-2):35-47

Lyons JJ, Waite GP, Ichihara M, Lees JM (2012) Tilt prior to explosions and the effect of topography on ultra-long-period seismic records at Fuego volcano, Guatemala. Geophys Res Lett 39(8):L08305

Maeda Y, Takeo M (2011) Very-long-period pulses at Asama volcano, central Japan, inferred from dense seismic observations. Geophys J Int 185(1):265-282

Maeda Y, Kato A, Terakawa T, Yamanaka Y, Horikawa S, Matsuhiro K, Okuda T (2015a) Source mechanism of a VLP event immediately before the 2014 eruption of Mt. Ontake, Japan. Earth Planets Space 67(1):187. https://doi. org/10.1186/s40623-015-0358-0

Maeda Y, Kumagai H, Lacson R, Figueroa MS, Yamashina T, Ohkura T, Baloloy AV (2015b) A phreatic explosion model inferred from a very long period seismic event at Mayon Volcano, Philippines. J Geophys Res Solid Earth 120(1):226-242

Mastin L, Witter J (2000) The hazards of eruptions through lakes and seawater. J Volcanol Geotherm Res 97(1):195-214

Matoza RS, Chouet BA (2010) Subevents of long-period seismicity: implications for hydrothermal dynamics during the 2004-2008 eruption of Mount St. Helens. J Geophys Res Solid Earth 115(B12):B12206
Merian J (1828) Ueber die Bewegung tropfbarer Flüssigkeiten in Gefässen [On the motion of drippable liquids in containers. Ph.D. thesis, Basel, Schweighauser

McNamara D, Ringler A, Hutt C, Gee L (2011) Seismically observed seiching in the Panama Canal. J Geophys Res Solid Earth 116(B4):B04312

Morioka H, Kumagai H, Maeda T (2017) Theoretical basis of the amplitude source location method for volcano-seismic signals. J Geophys Res Solid Earth 122(8):6538-6551

Neuberg J, Pointer T (2000) Effects of volcano topography on seismic broad-band waveforms. Geophys J Int 143(1):239-248

Neuberg J, Luckett R, Ripepe M, Braun T (1994) Highlights from a seismic broadband array on Stromboli volcano. Geophys Res Lett 21(9):749-752

Neuberg JW, Tuffen H, Collier L, Green D, Powell T, Dingwell D (2006) The trigger mechanism of low-frequency earthquakes on Montserrat. J Volcanol Geotherm Res 153(1):37-50

O'Brien G, Bean C (2008) Seismicity on volcanoes generated by gas slug ascent. Geophys Res Lett 35(16):L16308

Ogiso M, Matsubayashi H, Yamamoto T (2015) Descent of tremor source locations before the 2014 phreatic eruption of Ontake volcano, Japan. Earth Planets Space 67(1):206. https://doi.org/10.1186/s40623-015-0376-y

Ohminato T (2006) Characteristics and source modeling of broadband seismic signals associated with the hydrothermal system at Satsuma-Iwojima volcano, Japan. J Volcanol Geotherm Res 158(3):467-490

Rouwet D, Sandri L, Marzocchi W, Gottsmann J, Selva J, Tonini R, Papale P (2014) Recognizing and tracking volcanic hazards related to non-magmatic unrest: a review. J Appl Volcanol 3(1):17

Scherbaum F, Johnson J, Rietbrock A (1992) Programmable interactive toolbox for seismological analysis. Seismological Society of America, Albany

Stevenson DS, Blake S (1998) Modelling the dynamics and thermodynamics of volcanic degassing. Bull Volcanol 60(4):307-317

Stix J, de Moor JM (2018) Understanding and forecasting phreatic eruptions driven by magmatic degassing. Earth Planets Space 70(1):83. https://doi. org/10.1186/s40623-018-0855-Z (in press)

Surono, Jousset P, Pallister J, Boichu M, Buongiorno MF, Budisantoso A, Costa F, Andreastuti S, Prata F, Schneider D, Clarisse L, Humaida H, Sumarti S, Bignami C, Griswold J, Carn S, Oppenheimer C, Lavigne F (2012) The 2010 explosive eruption of java's merapi volcano-a'100-year' event. J Volcanol Geotherm Res 241-242:121-135

Taisne B, Brenguier F, Shapiro N, Ferrazzini V (2011) Imaging the dynamics of magma propagation using radiated seismic intensity. Geophys Res Lett 38:L04304

Takano B, Suzuki K, Sugimori K, Ohba T, Fazlullin S, Bernard A, Sumarti S, Sukhyar R, Hirabayashi M (2004) Bathymetric and geochemical investigation of Kawah ljen crater lake, East Java, Indonesia. J Volcanol Geotherm Res 135(4):299-329

Thiéry R, Mercury L (2009a) Explosive properties of water in volcanic and hydrothermal systems. J Geophys Res Solid Earth 114(B5):B05205

Thiéry R, Mercury L (2009b) Explosivity conditions of aqueous solutions. J Solut Chem 38(7):893-905

Vandemeulebrouck J, Sohn RA, Rudolph ML, Hurwitz S, Manga M, Johnston MJ, Soule SA, McPhee D, Glen JM, Karlstrom L et al (2014) Eruptions at Lone Star geyser, Yellowstone National Park, USA: 2. Constraints on subsurface dynamics. J Geophys Res Solid Earth 119(12):8688-8707

Wagner W, Pruß A (2002) The IAPWS formulation 1995 for the thermodynamic properties of ordinary water substance for general and scientific use. J Phys Chem Ref Data 31(2):387-535

Werner C, Hurst T, Scott B, Sherburn S, Christenson B, Britten K, Cole-Baker J, Mullan B (2008) Variability of passive gas emissions, seismicity, and deformation during crater lake growth at White Island Volcano, New Zealand, 2002-2006. J Geophys Res Solid Earth 113(B1):B01204

Wielandt E, Forbriger T (1999) Near-field seismic displacement and tilt associated with the explosive activity of Stromboli. Ann Geofis 42(3):407-416 